\title{
Time-Resolved Microscopic Imaging of Laser-Induced Material Modifications in Optical Materials
}

R. A. Negres

June 16, 2010

Time-Resolved Microscopic Imaging of Laser-Induced Material Modifications in Optical Materials San Jose, CA, United States May 16, 2010 through May 21, 2010 
This document was prepared as an account of work sponsored by an agency of the United States government. Neither the United States government nor Lawrence Livermore National Security, LLC, nor any of their employees makes any warranty, expressed or implied, or assumes any legal liability or responsibility for the accuracy, completeness, or usefulness of any information, apparatus, product, or process disclosed, or represents that its use would not infringe privately owned rights. Reference herein to any specific commercial product, process, or service by trade name, trademark, manufacturer, or otherwise does not necessarily constitute or imply its endorsement, recommendation, or favoring by the United States government or Lawrence Livermore National Security, LLC. The views and opinions of authors expressed herein do not necessarily state or reflect those of the United States government or Lawrence Livermore National Security, LLC, and shall not be used for advertising or product endorsement purposes. 


\title{
Time-Resolved Microscopic Imaging of Laser-Induced Material Modifications in Optical Materials
}

\author{
Presentation to the \\ CLEO/QELS 2010 Conference

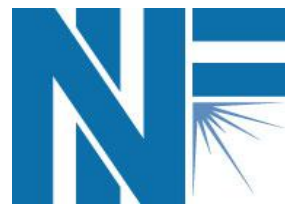 \\ Physical \\ Life Sciences
}

Raluca A. Negres

Lawrence Livermore National Laboratory

May 17, 2010 
- Materials science problem: localized energy deposition $\rightarrow$ sequence of transient material modifications and formation of a void

- Energy coupling mechanisms

- Solid state material response to localized extreme conditions

- Energy transport through complex material phases

- Material displacement and lattice transformation

- Practical reasons:

- What causes and/or how to eliminate damage in optical components

- How damage evolves (timeline)

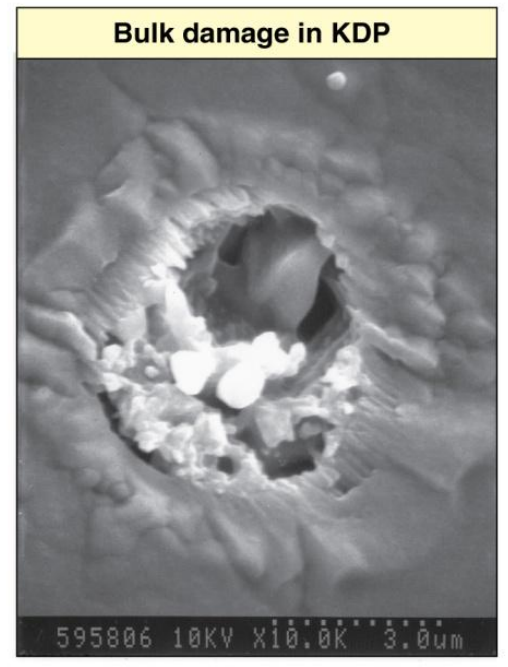

Carr et al., APL, 89, 131901 (2006)

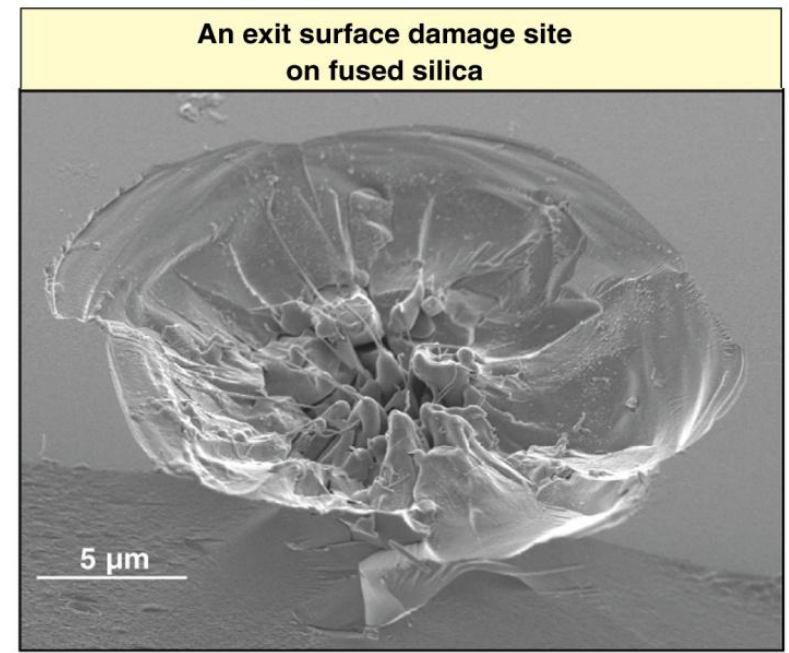

Wong et al., J. Non. Cryst. Solids, 352, 255 (2006) 


\section{Objectives}

- We want to elucidate the processes involved during a damage event in optical materials

- Develop the experimental capabilities to measure the relevant processes with adequate resolution

- Use experimental results to validate theoretical models

Today I will discuss the material response during the cooling phase in bulk fused silica following localized energy deposition via ns laser-induced breakdown 


\section{Time-resolved microscopy system is used to image the evolution of bulk damage in $\mathrm{SiO}_{2}$}

\section{POLARIZATION SENSITIVE SYSTEM TRANSMISSION GEOMETRY}

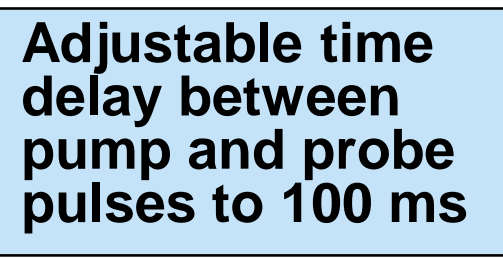

\section{Polarizing} cube beam

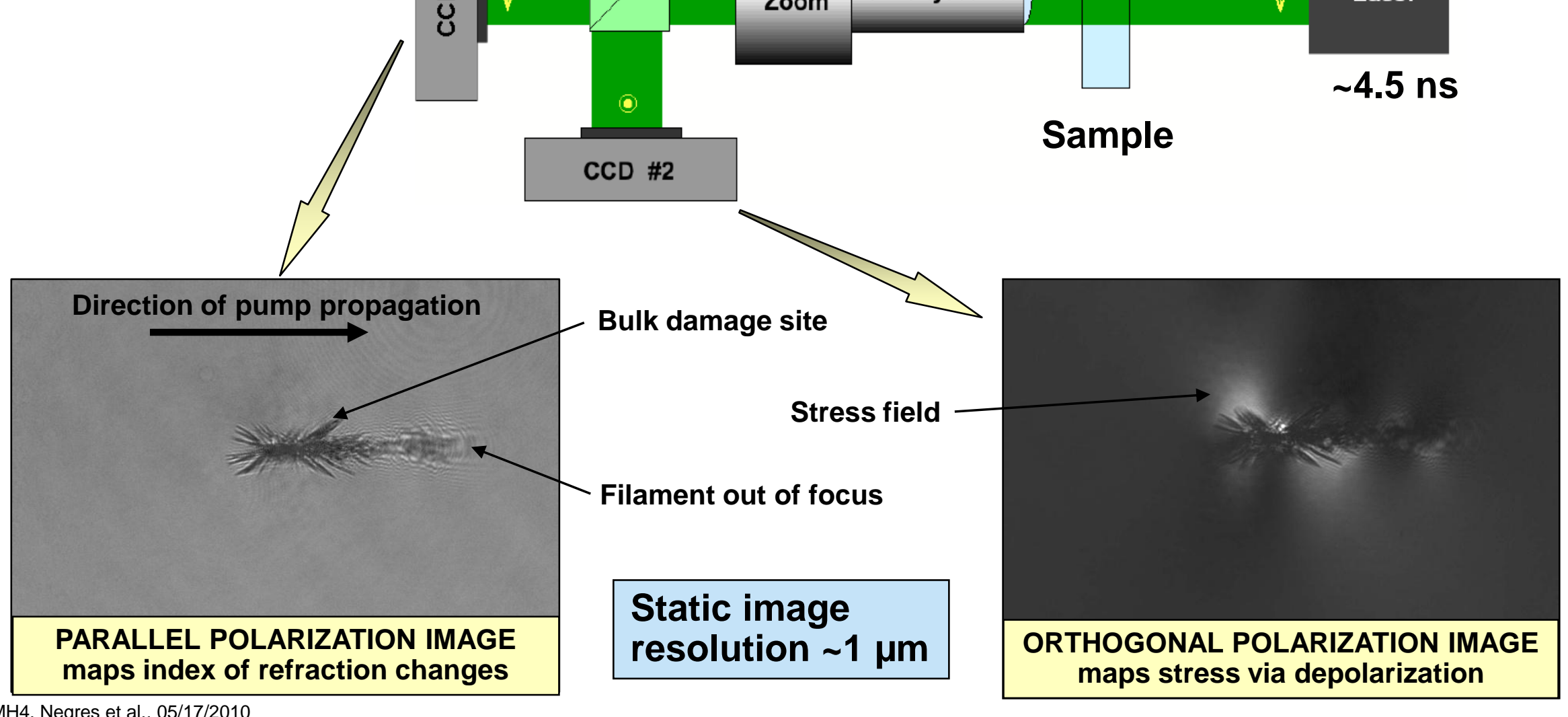

Bulk damage site splitter 


\section{Images at different delays reveal the material response during the entire timeline of bulk damage}

1) Shock fronts 2) Initiation and propagation of cracks

3) Transient absorption at crack and core regions 4) Return to solid phase
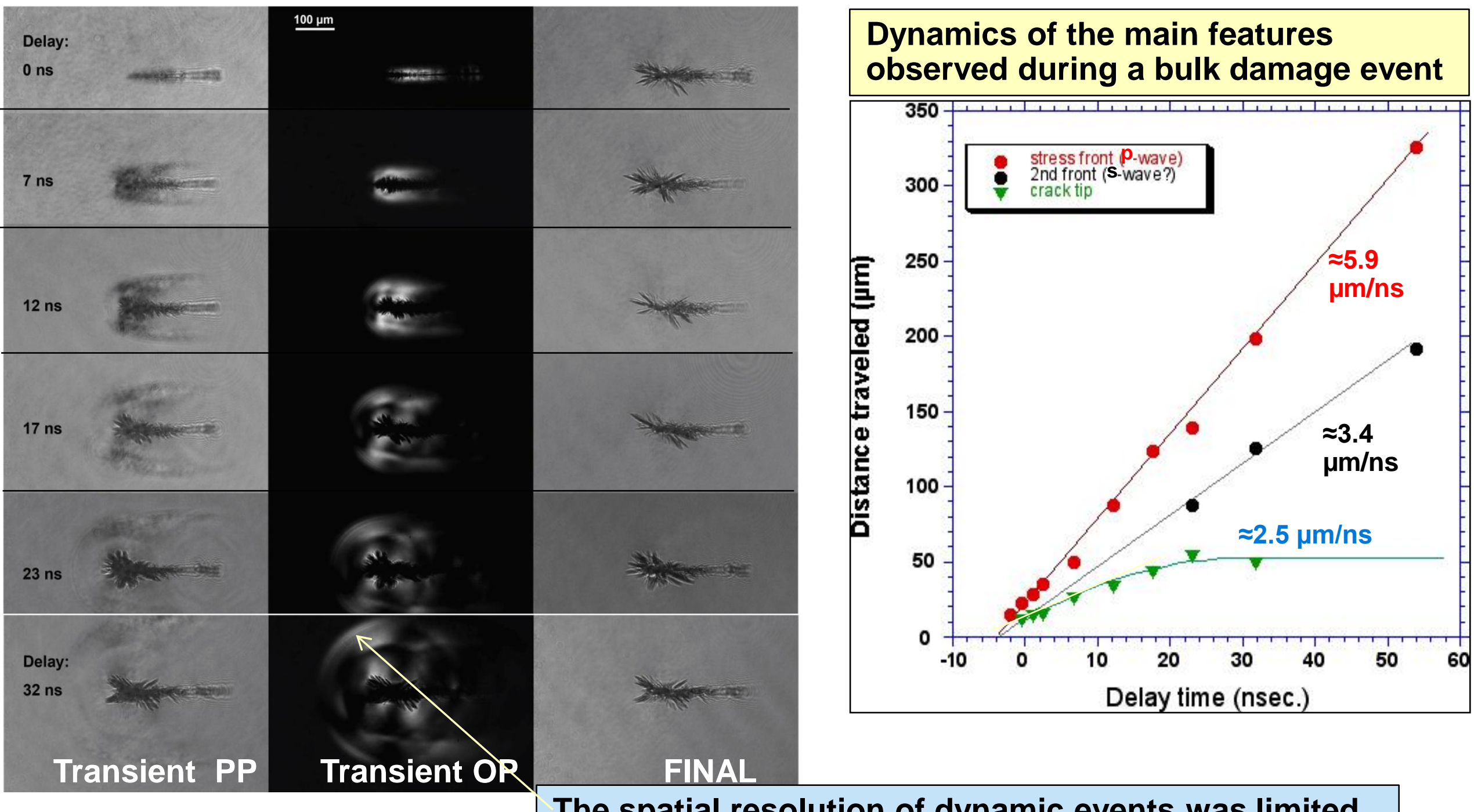

Transient OR

FINAL

The spatial resolution of dynamic events was limited at the time by the pulse length of the probe pulse $<5>$ 


\section{Images at different delays reveal the material response during the entire timeline of bulk damage}

1) Shock fronts 2) Initiation and propagation of cracks

3) Transient absorption at crack and core regions 4) Return to solid phase

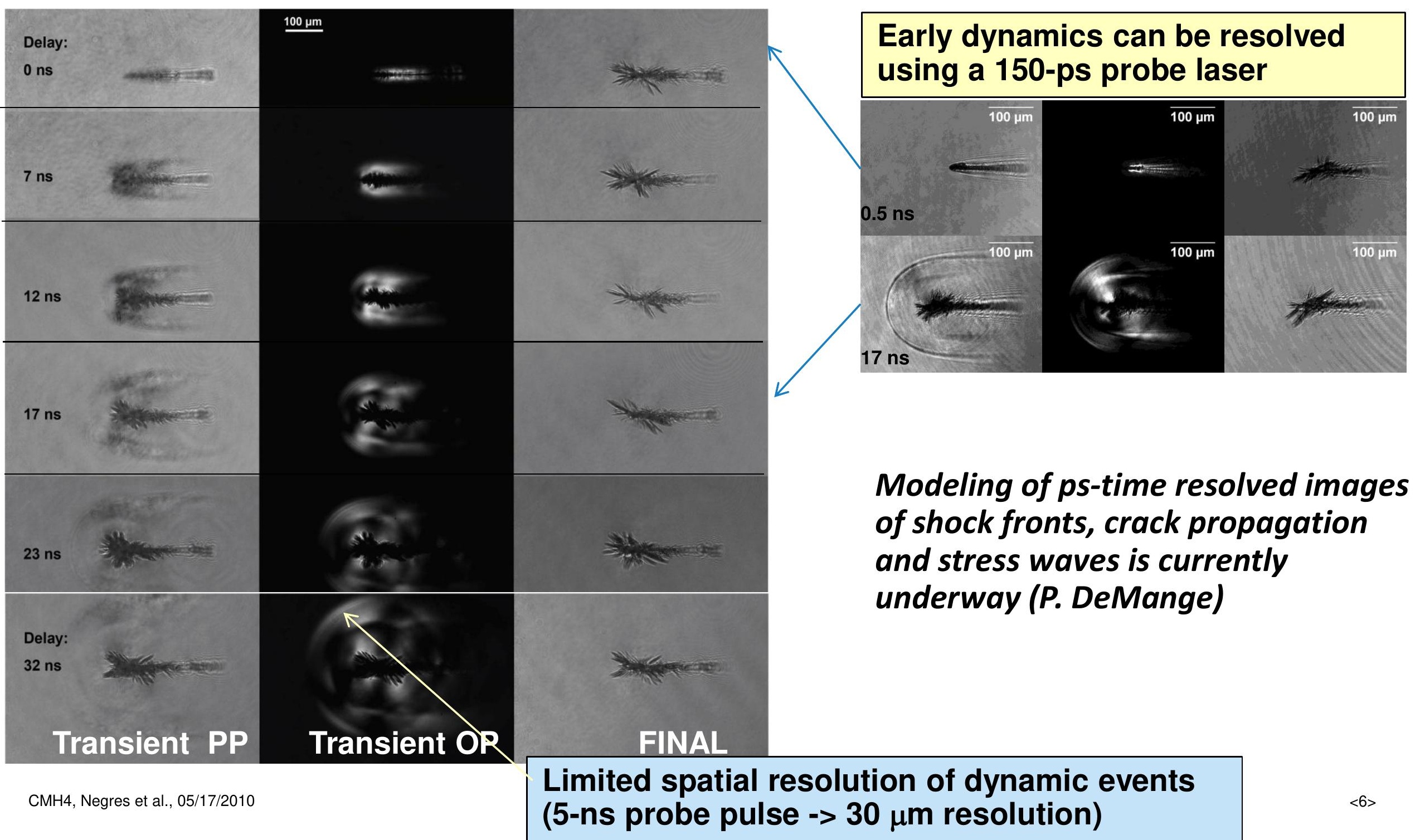




\section{In the following, I will discuss the material}

response during the cooling phase

1) Shock fronts 2) Initiation and propagation of cracks

3) Transient absorption at crack and core regions 4) Return to solid phase

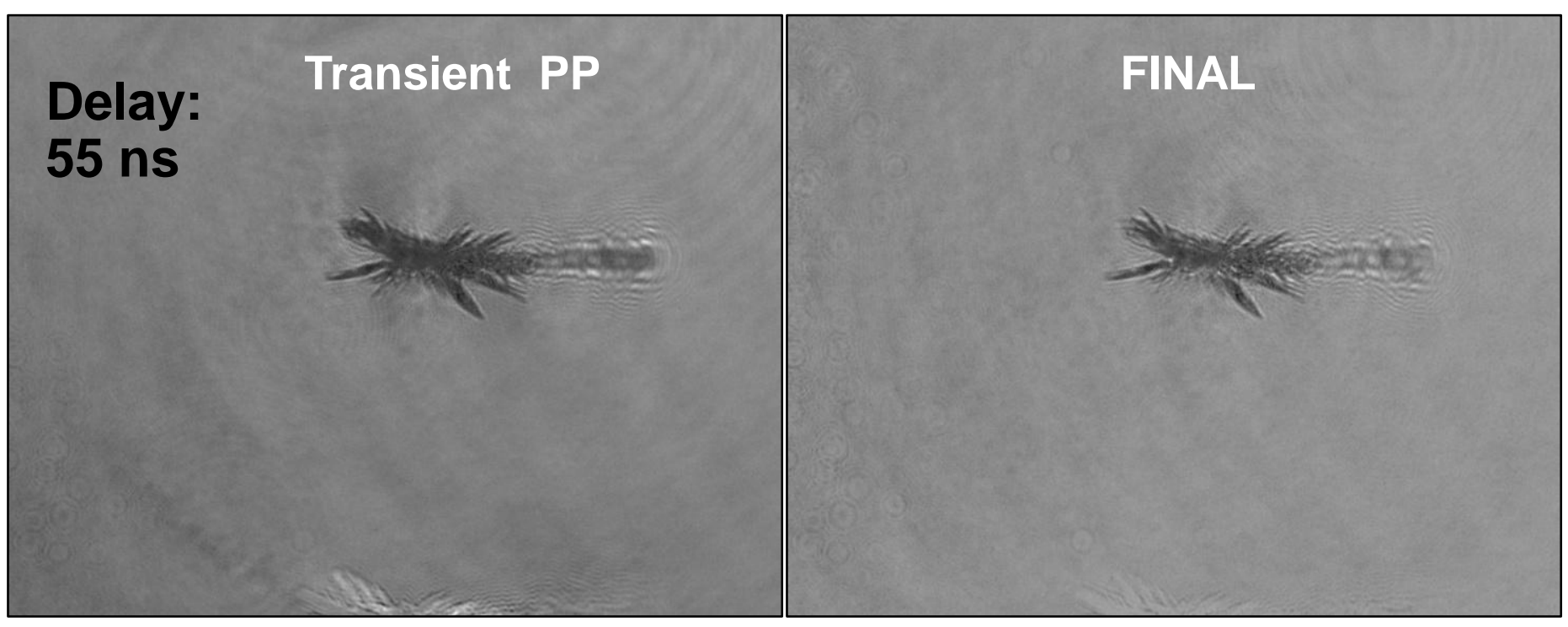

- Results suggest that crack growth proceeds up to $\sim 30$ ns delay

- At delays longer than $\sim 50 \mathrm{~ns}$, the transient overall dimensions of the damage site appear the same as the final

- However, the contrast between the transient and final images (in the parallel polarization) is different 


\section{Ratio TR (final/transient) images highlight the locations of the transient absorption \\ locations of the transient absorption}
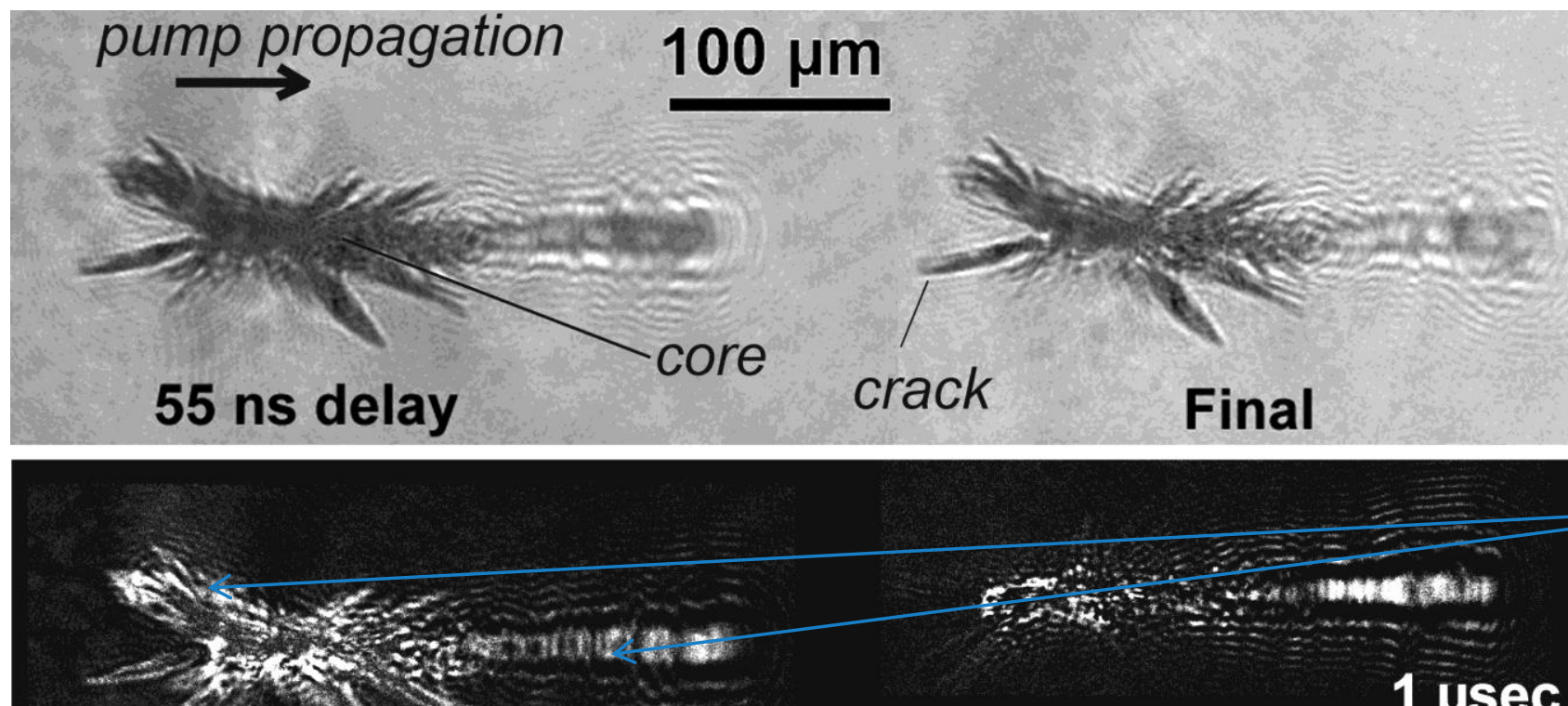

$55 \mathrm{~ns}$

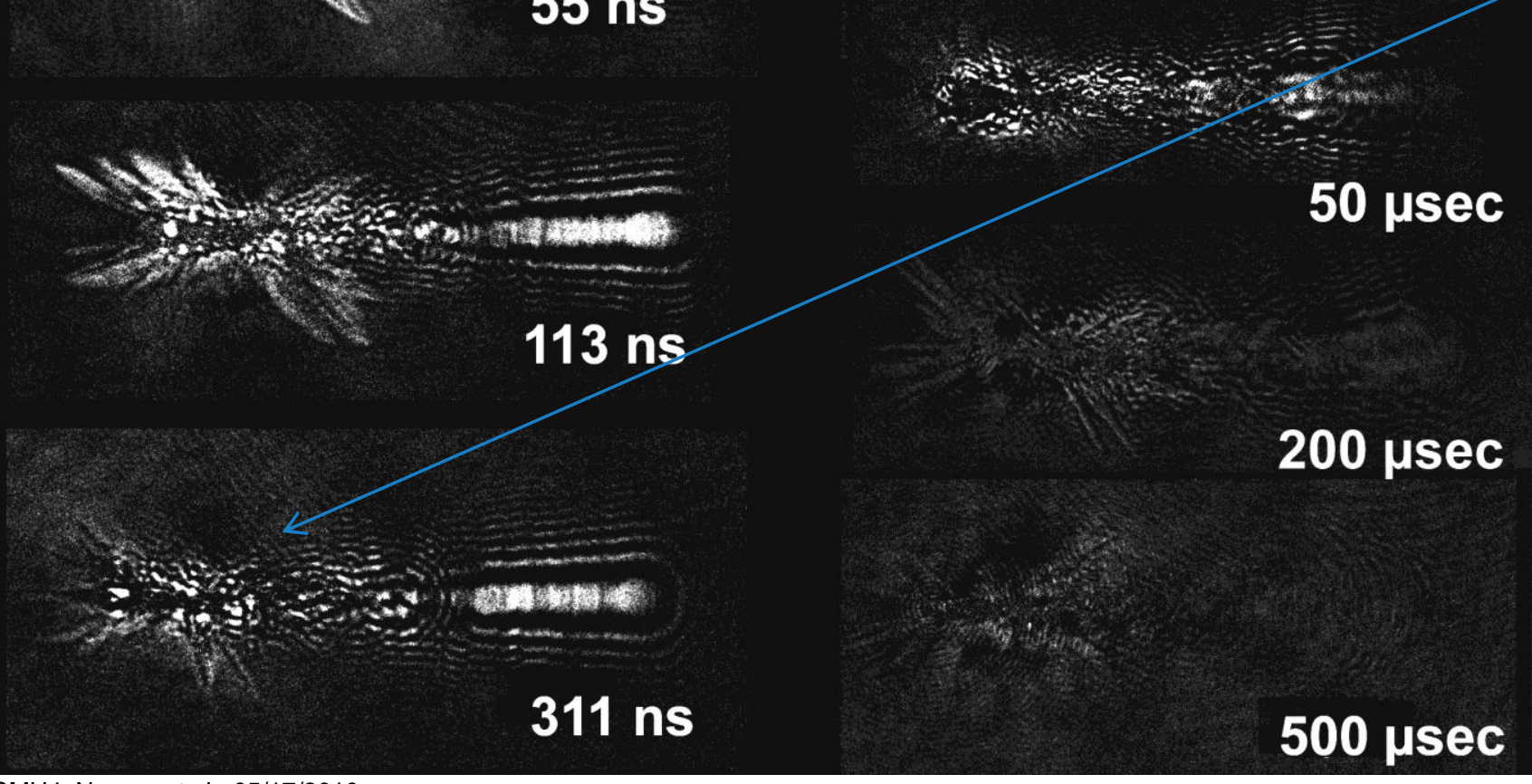

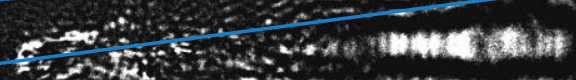

1 usec

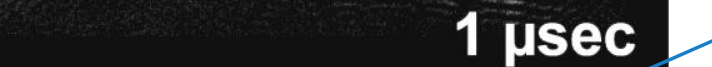

50 usec

500 usec
- Cracks and core region absorb light

- Absorption by cracks stops at $\sim 300 \mathrm{~ns}$ 


\section{Ratio TR images highlight the locations of the transient absorption

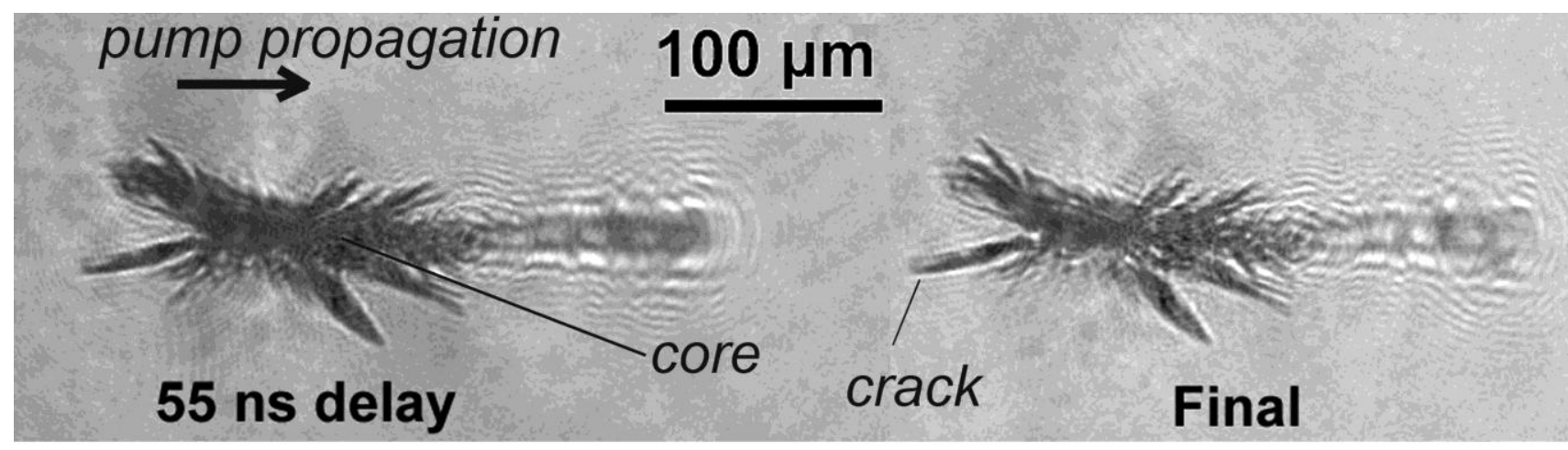

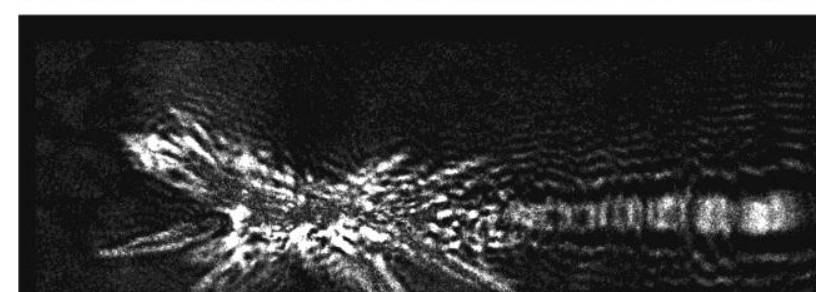

55 ns

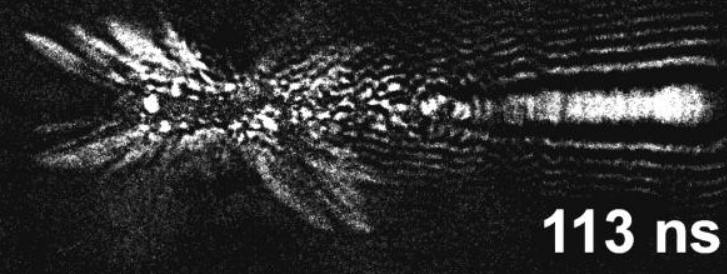

$113 \mathrm{~ns}$
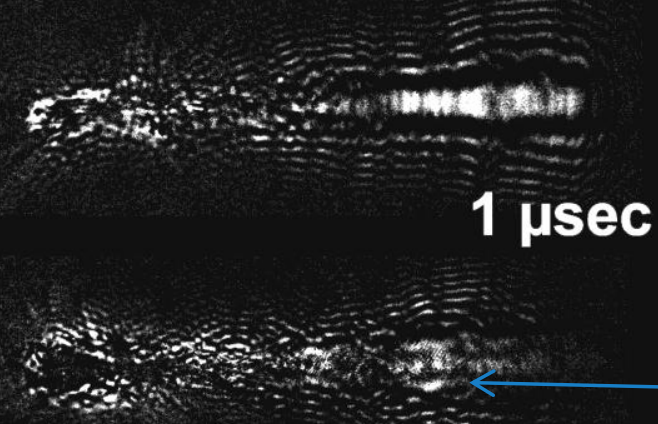

50 usec

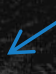

200 Hsec
- Cracks and core region absorb light

- Absorption by cracks stops at $~ 300$ ns

- The core region is also associated with a transient absorption for a much longer time, up to $\sim 200 \mu s$ 


\section{Ratio TR images highlight the locations of the transient absorption}

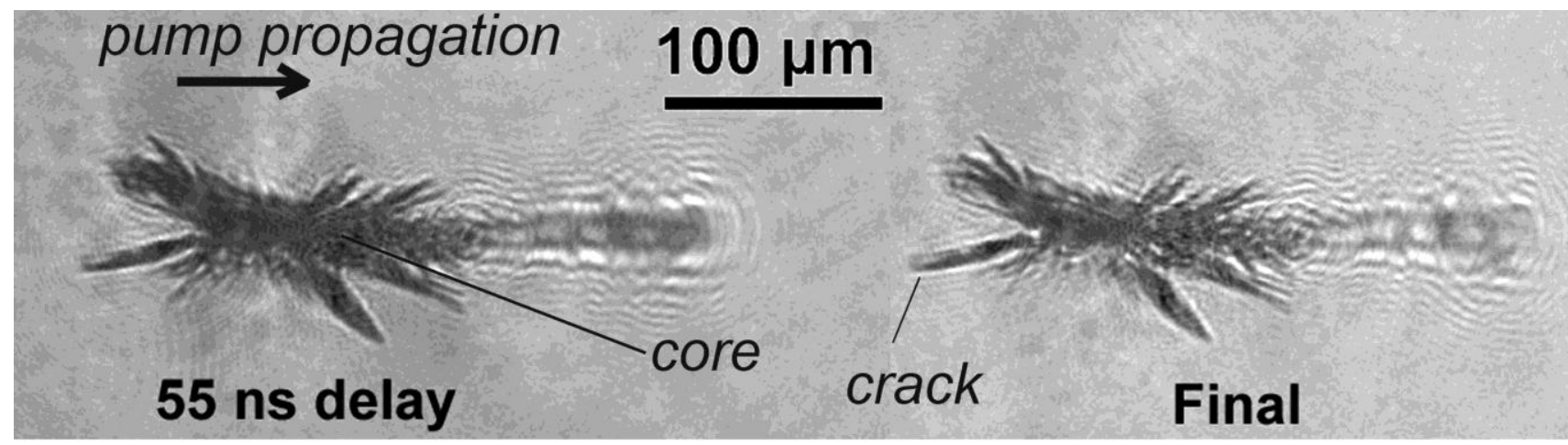

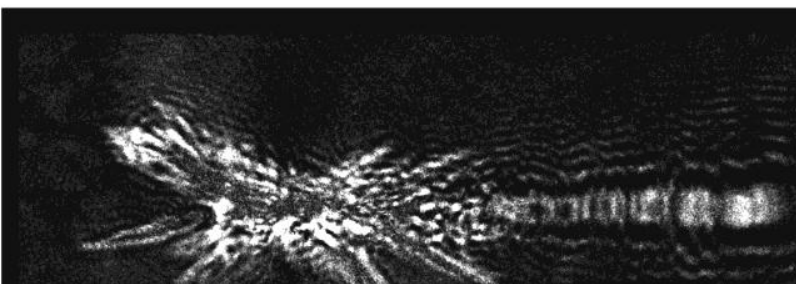

55 ns

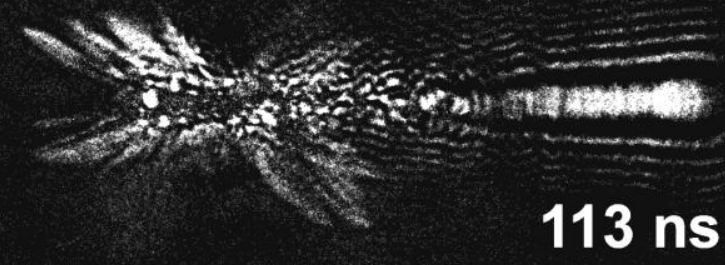

113 ns
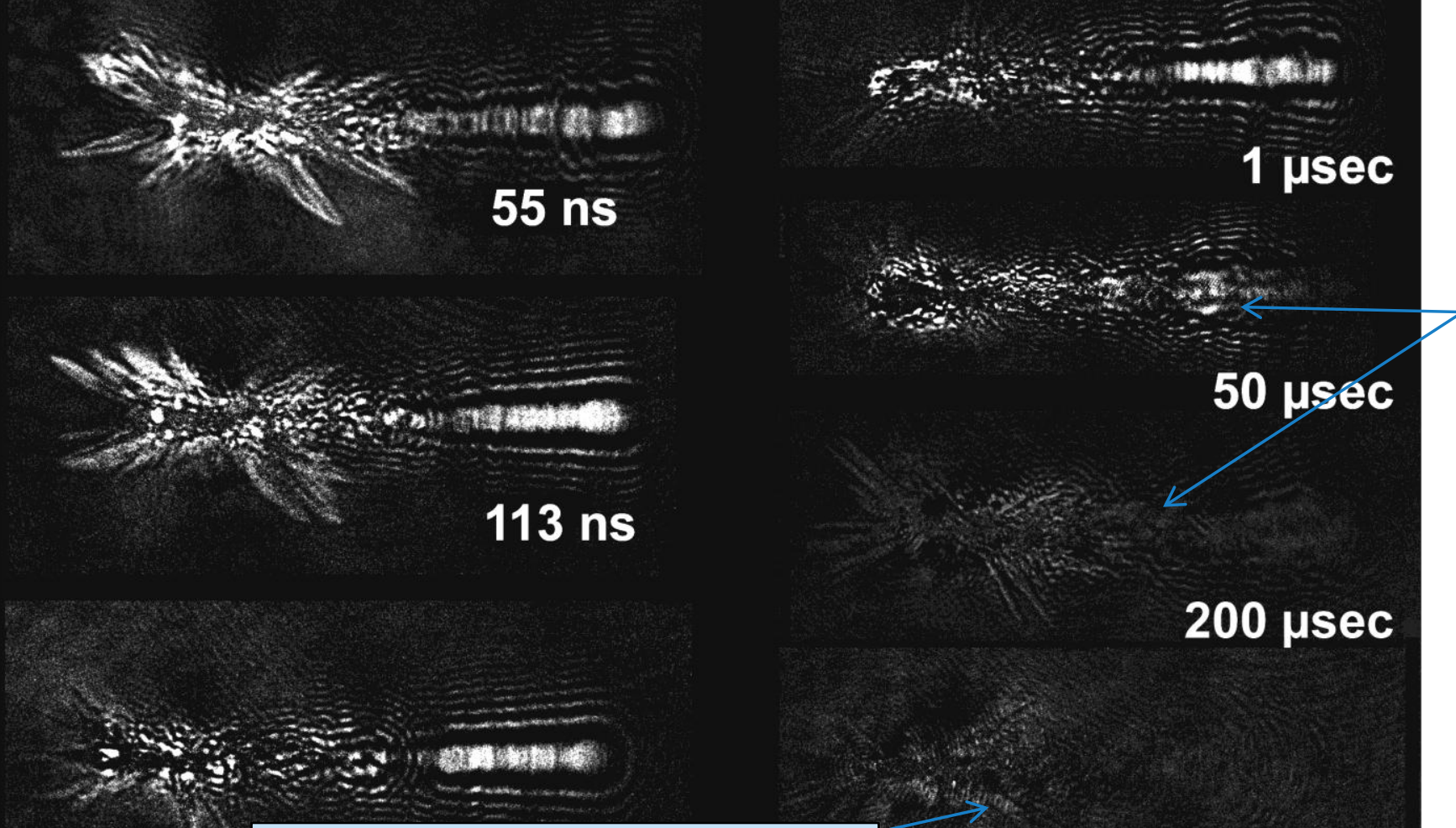

Image at $\mathbf{5 0 0 \mu s e c ~ d e l a y ~}$ suggest that the final state has been reached
50 usec

$200 \mu s e c$

- Cracks and core region absorb light

- Absorption by cracks stops at $~ 300$ ns

- The core region is also associated with a transient absorption for a much longer time, up to $150 \mu s$

- We postulate that the material in the core region is in a liquid or vapor phase at high $\mathrm{T}^{1,2}$

500 usec
1,2Proc. SPIE 5273, 74 (2004) and Proc. SPIE 6720, 672009 (2007) 
The last step in the damage process is returning of the "core" region to solid phase

Hypothesis: This phase change will lead to changes in the scattering properties of the material

Our imaging system can be re-configured to a back-scattering geometry (BS)

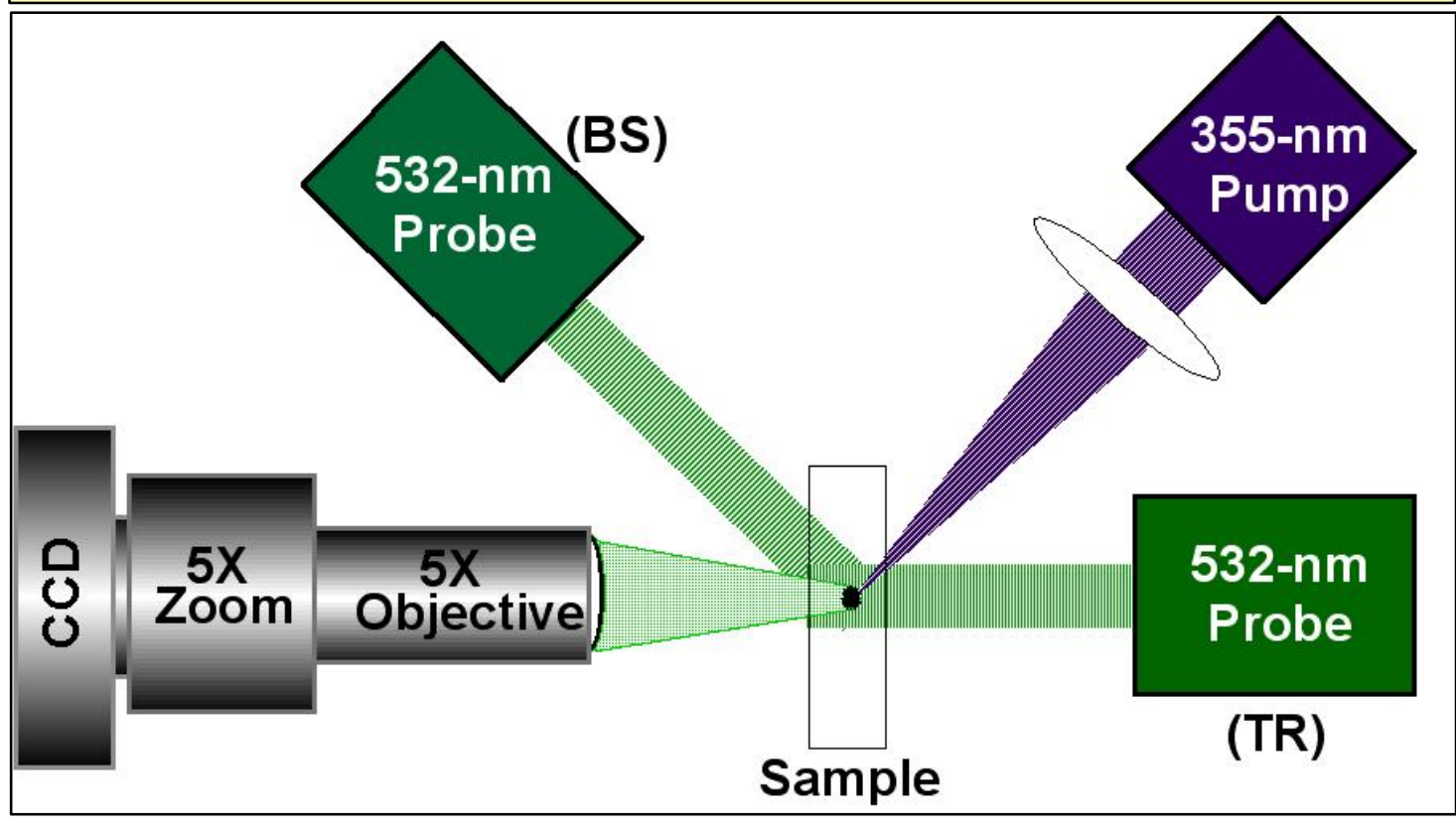

- This scattering effect may be due to microvoid formation by volume contraction during cooling of the material in liquid phase ${ }^{3,4}$

- This effect terminates at about $70 \mathrm{msec}$ delay
Ratio BS images highlight the locations of transient scattering

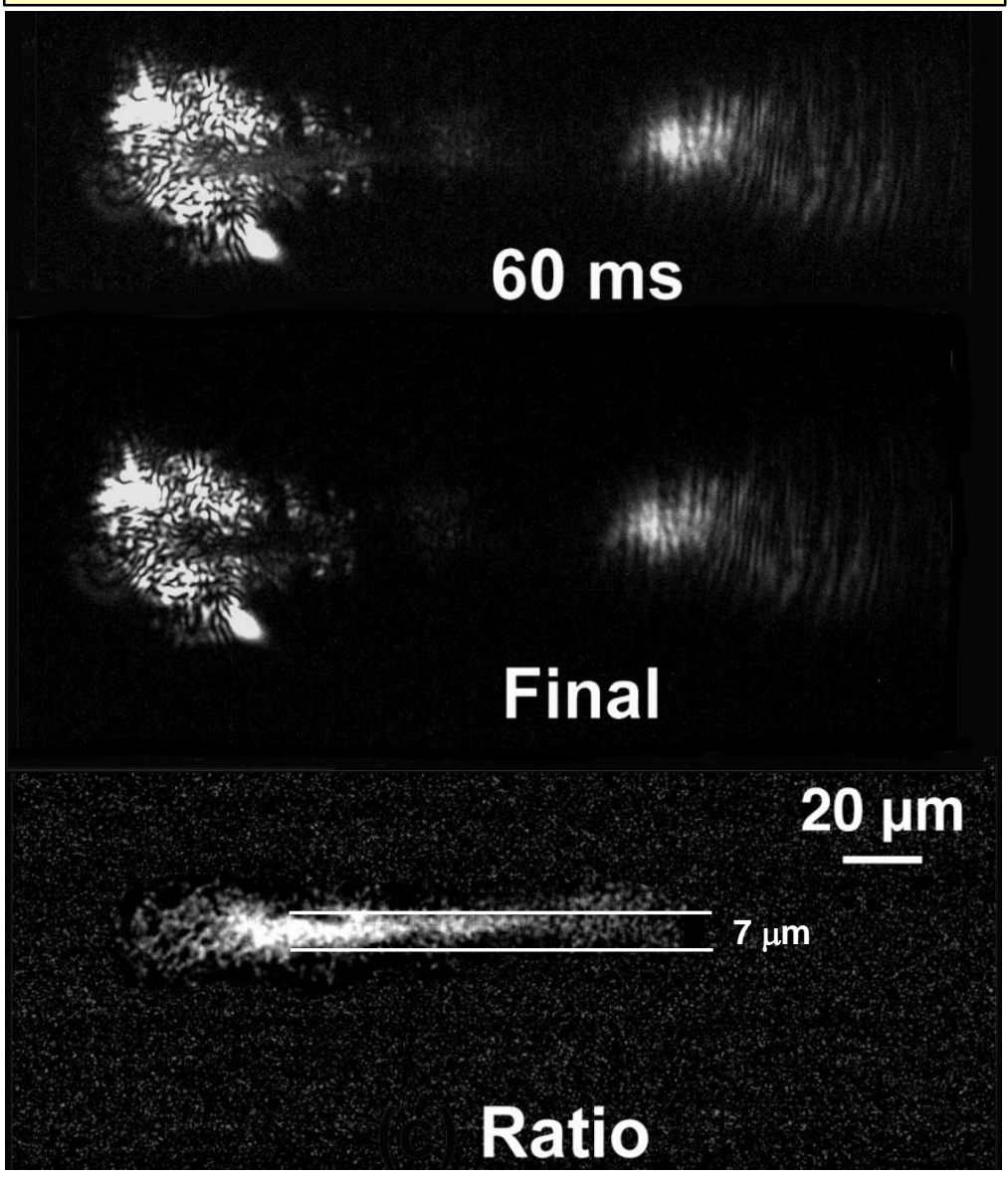

3,4Phys. Rev. Lett. 97, 025502 (2006) and 100, 135502 (2008) 


\section{We use a pump and probe damage testing system to differentiate between the loss mechanisms}

Transient images revealed changes in the absorption and/or scattering of the probe laser light incident upon the damaged volume

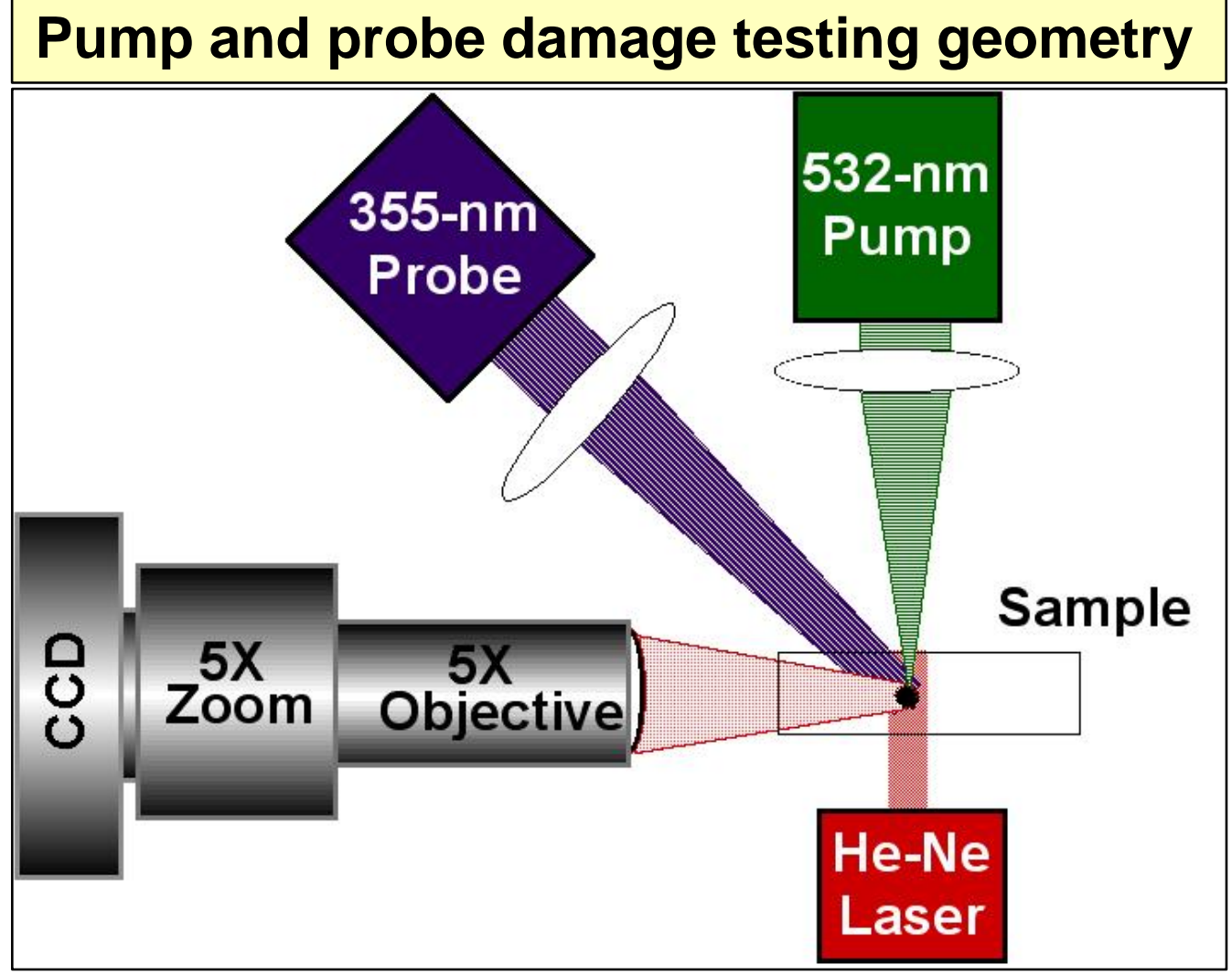

We indirectly monitor the transient absorption (not scattering) in the damaged region
- The presence of enhanced absorption by the host material due to the pump will lead to higher energy deposition by the probe pulse

- This effect will be manifested as a larger in size damage site from the combined exposure to both pump and probe pulses 


\section{We compare the dynamic images of bulk damage with the pump-probe damage testing results ${ }^{5}$}

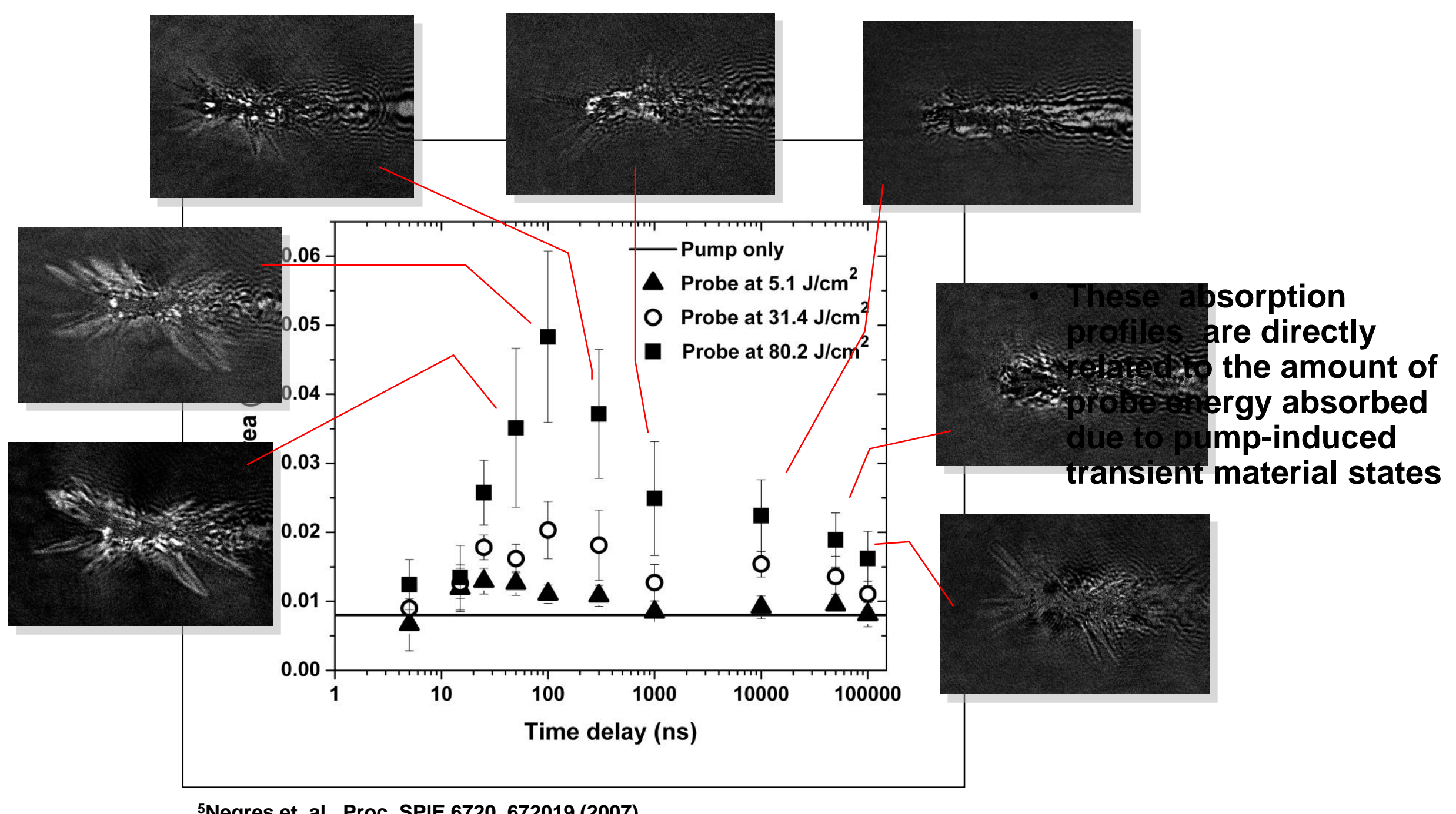

${ }^{5}$ Negres et. al., Proc. SPIE 6720, 672019 (2007)

Combined results confirm the presence of transient absorption in the pump-induced modified material volume (cracks \& "core" regions) 


\section{We extrapolate temperatures along the timeline based on the temporal behavior of the emission ${ }^{6}$ during a bulk damage event in $\mathrm{SiO}_{2}$}
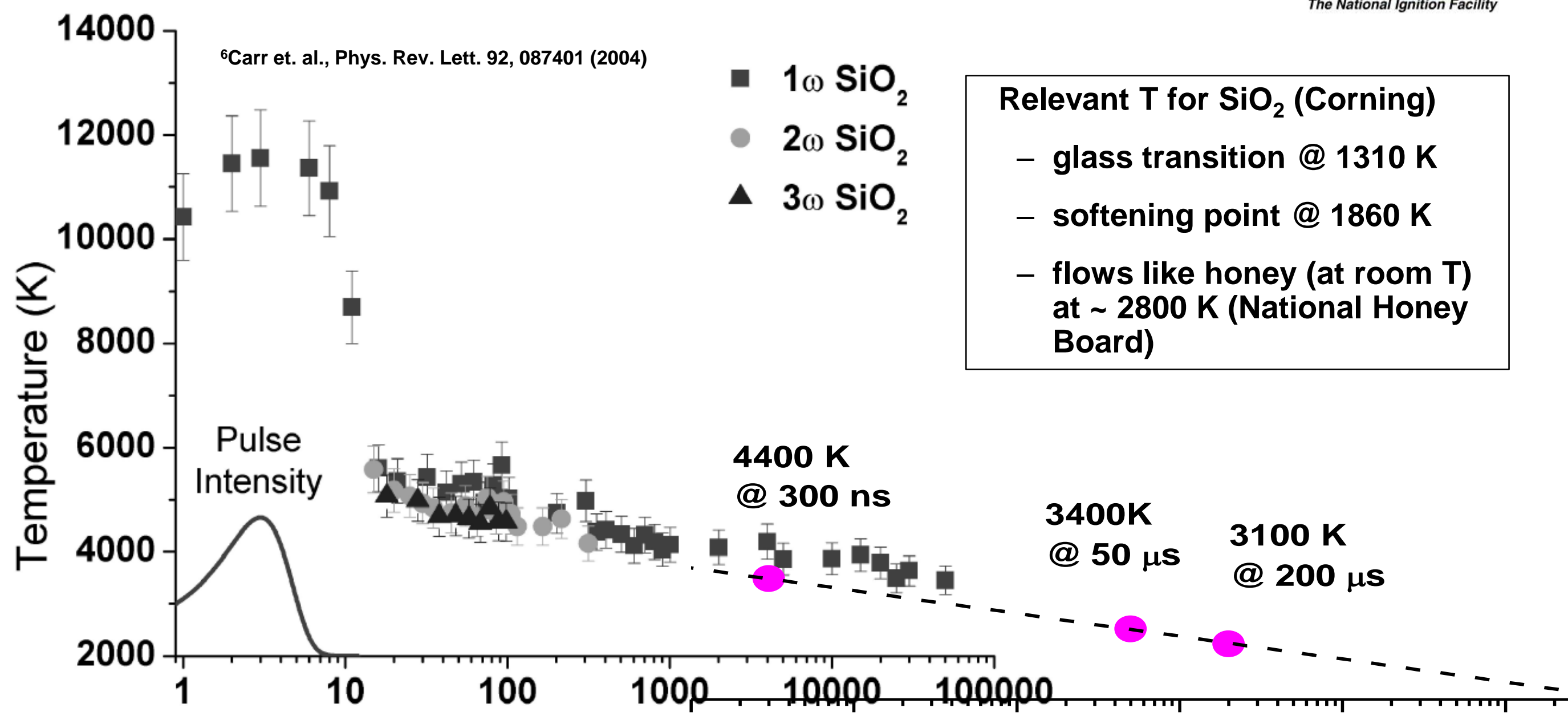

Delay Time (ns)

The return of the melted material to solid phase at $\sim 70 \mathrm{~ms}$ (as suggested in BS images) and the estimated $\mathrm{T}$ are in excellent agreement with the softening point of $\mathrm{SiO}_{2}$
- The transformation of silica at high $\mathrm{T}$ to a more absorptive material phase has been previously suggested 7,8

7,8Phys. Rev. B 62, 8584 (2000) and Proc. SPIE 6720, 672009 (2007) 


\section{We correlate previous observations to the microscopic structure of the bulk damage site}

SEM images of the axial cross section of a bulk damage site in fused silica

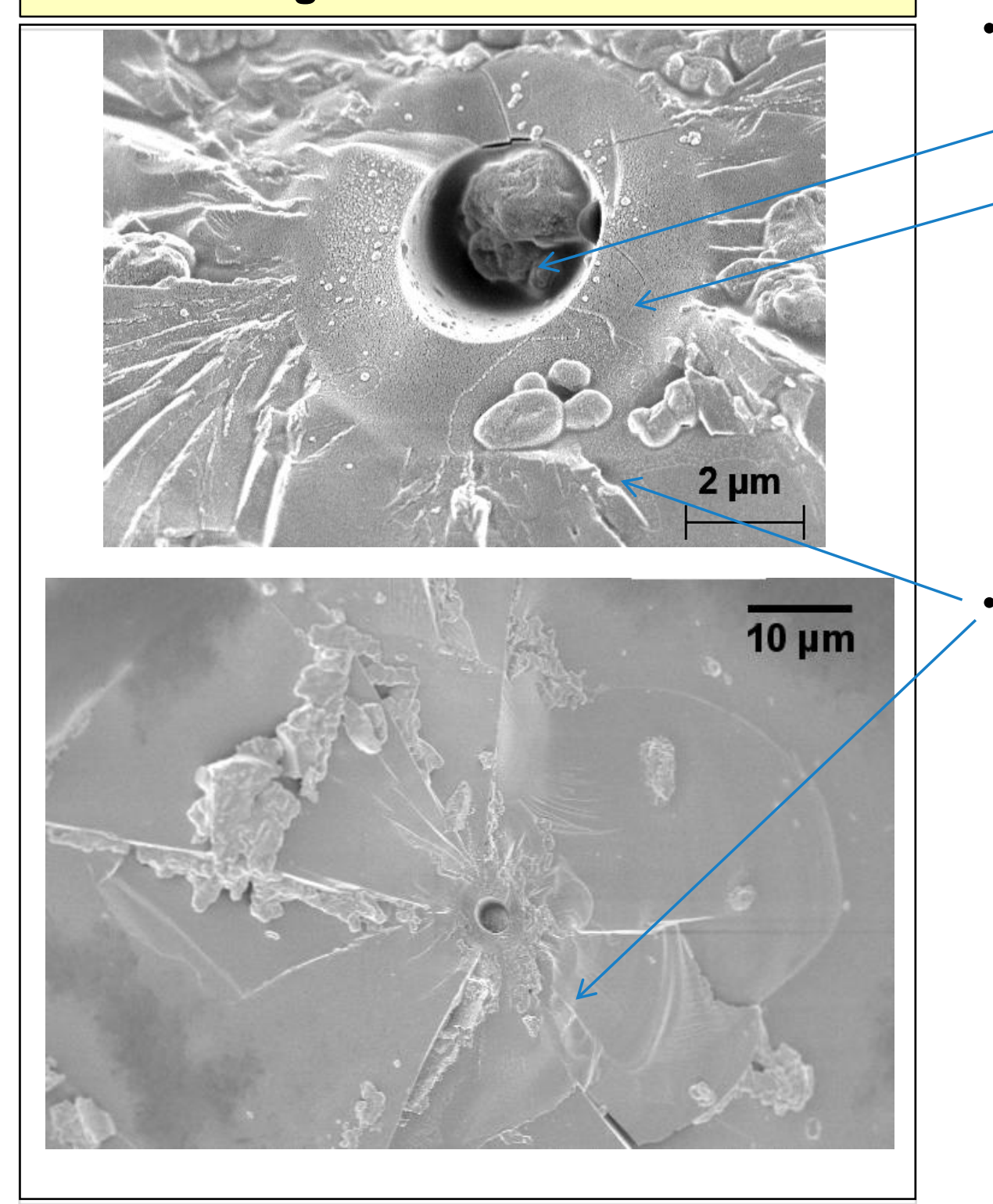

- The core region is about $7 \mu \mathrm{m}$ in diameter

- contains a cavity ( 3-4 $\mu \mathrm{m}$ in diameter)

- the outer ring is homogeneous suggesting that it was formed at a later time

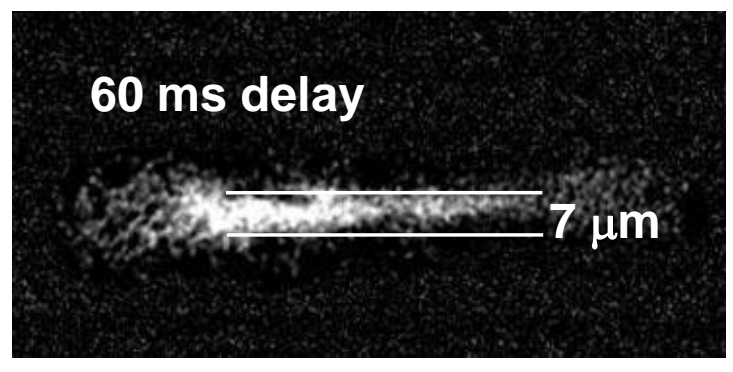

Mechanically damaged region (due to the shockwave propagation following the initial energy deposition) was formed earlier (at times shorter than $50 \mathrm{~ns}$ ) and extends out to $\sim 100 \mu \mathrm{m}$ 
- We have developed an experimental system capable of imaging bulk damage evolution with adequate spatial and temporal resolution

- The results reveal the salient behaviors associated with the material response during the cooling phase:

- The mechanically damaged region is forming at times shorter than $\mathbf{5 0}$ ns

- A large population of defects is established in the cracked region and decays within 300 ns

- There is a core region that remains in a high temperature, liquid-gas state and exhibits a strong transient absorption for about $200 \mu \mathrm{s}$

- The material returns to solid phase at $\sim 70$ ms delay after laser energy deposition

- Future work is aimed at:

- Resolving the shockwave physical dimensions and early dynamics

- Formation dynamics and absorption characteristics of electronic excitation region

- Employ hydrodynamic codes to model experimental observations and develop reliable theoretical models for this intermediate physical regime between cold materials and HED matter 